\title{
The molecular fingerprint of bicuspid aortopathy
}

\author{
Paul W. M. Fedak, MD, PhD, FRCSC, ${ }^{\text {a,b }}$ and Subodh Verma, MD, PhD, FRCSC ${ }^{\mathrm{c}, \mathrm{d}}$
}

Surgical treatments for thoracic aneurysmal diseases have evolved rapidly. Technical innovations in open repairs (David aortic valve-sparing root replacement) and minimal access endovascular procedures (thoracic endovascular aortic repair) have improved patient outcomes substantially. Unfortunately, our understanding of the molecular and cellular mechanisms that trigger aortic remodeling and aneurysm formation have not been as progressive as the surgical approaches to the same problem. The complex aortopathy associated with bicuspid aortic valves is of growing interest to both surgeons and scientists. ${ }^{1}$ Others and we have demonstrated the activation of unique molecular pathways that control extracellular matrix (ECM) regulation in patients that may trigger and coordinate the progressive aortic thinning and dilatation associated with bicuspid aortic valve disease. ${ }^{2,3}$ An improved understanding of these pathways has clinical relevance to surgeons. With this knowledge, it may be possible to predict the progression of aortic dilatation, and in so doing guide both the timing and extent of aortic resection for individual patients. The current guidelines for aortic resection in patients with aortopathy are too simple. Contemporary guidelines rely exclusively on aortic dimensions without accounting for the degree of underlying aortopathy (tissue characteristics), disease phenotype (pattern of cusp fusion), or hemodynamic shear stress at the level of an individual patient. Personally tailored approaches for patients with bicuspid aortic syndrome are crucial because the disease is clinically heterogeneous, making individual predictions particularly challenging. ${ }^{4}$

In their report in this issue of the Journal, Ikonomidis and colleagues provide a unique set of clinical data that may facilitate a more accurate and scientific approach to patients with bicuspid aortic valves. In the search for predictive biomarkers, these investigators wisely examined previously implicated ECM regulatory molecules. In addition, a profile of microRNA molecules were evaluated because of their

\footnotetext{
From the Bicuspid Aortic Valve Program, ${ }^{\text {a }}$ Bluhm Cardiovascular Institute, Northwestern Memorial Hospital, Northwestern University, Chicago, Ill; the Libin Cardiovascular Institute of Alberta, ${ }^{\mathrm{b}}$ University of Calgary, Calgary, Alberta, Canada; the Division of Cardiac Surgery, ${ }^{c}$ Keenan Research Centre in the Li Ka Shing Knowledge Institute at St Michael's Hospital, Toronto, Ontario, Canada; and the Department of Surgery, ${ }^{\mathrm{d}}$ University of Toronto, Toronto, Ontario, Canada.

Disclosures: Authors have nothing to disclose with regard to commercial support. Received for publication Feb 8, 2013; accepted for publication Feb 27, 2013.

Address for reprints: Subodh Verma, MD, PhD, FRCSC, Division of Cardiac Surgery, St Michael's Hospital, Suite 8-003, Bond Wing, 30 Bond St, Toronto, Ontario M5B 1W8, Canada (E-mail: vermasu@smh.ca).

J Thorac Cardiovasc Surg 2013;145:1334

$0022-5223 / \$ 36.00$

Copyright (c) 2013 by The American Association for Thoracic Surgery

http://dx.doi.org/10.1016/j.jtcvs.2013.02.067
}

critical role as regulators of ECM expression. ${ }^{5}$ This innovative work gives rise to numerous implications. First, these data confirm the important mechanistic role of ECM dysregulation in the bicuspid aorta, particularly the matrix metalloproteinase-2/tissue inhibitor of metalloproteinase-2 axis. The link between specific microRNA species and specific ECM proteases in patients with aortopathy requires further investigation. Second, the investigation demonstrates that the bicuspid valve aorta has a molecular signature different from that of the tricuspid valve aorta in both the local aortic and remote plasma compartments. These data provide a proof of concept and suggest that further work may be capable of validating specific circulating biomarkers for accurate prediction of future aortic events in patients with bicuspid aortopathy. A combination of circulating biomarkers with state-of-the art noninvasive structural and hemodynamic assessments, such as those obtained with 4-dimensional magnetic resonance imaging, ${ }^{6}$ might substantially alter the timing and extent of resection in patients at risk of aortic events.

In a recent survey, we were somewhat surprised to find a wide variation in surgeons' approaches to the aorta in patients with bicuspid valves. These approaches often went outside established guidelines, with marked differences in the timing, extent, and type of operative strategy of aortic resection. The work of Ikonomidis and colleagues brings us a step closer to establishing biomarkers as a predictive tool that may help define clinical phenotypes and establish best practices for surgical therapy for the large group of patients with bicuspid aortic valves.

\section{References}

1. Losenno KL, Goodman RL, Chu MW. Bicuspid aortic valve disease and ascending aortic aneurysms: gaps in knowledge. Cardiol Res Pract. 2012;2012:145202.

2. Ikonomidis JS, Jones JA, Barbour JR, Stroud RE, Clark LL, Kaplan BS, et al. Expression of matrix metalloproteinases and endogenous inhibitors within ascending aortic aneurysms of patients with bicuspid or tricuspid aortic valves. J Thorac Cardiovasc Surg. 2007;133:1028-36.

3. Fedak PW, de Sa MP, Verma S, Nili N, Kazemian P, Butany J, et al. Vascular matrix remodeling in patients with bicuspid aortic valve malformations: implications for aortic dilatation. J Thorac Cardiovasc Surg. 2003;126:797-806

4. Fedak PW. Bicuspid aortic valve syndrome: heterogeneous but predictable? Eur Heart J. 2008;29:432-3.

5. Boon RA, Seeger T, Heydt S, Fischer A, Hergenreider E, Horrevoets AJ, et al. MicroRNA-29 in aortic dilation: implications for aneurysm formation. Circ Res. 2011;109:1115-9.

6. Barker AJ, Markl M, Bürk J, Lorenz R, Bock J, Bauer S, et al. Bicuspid aortic valve is associated with altered wall shear stress in the ascending aorta. Circ Cardiovasc Imaging. 2012;5:457-66. 